\title{
Uji Aktivitas Antibakteri Fraksi Daun Sesewanua (Clerodendron squamatum Vahl.) Terhadap Bakteri Streptococcus mutans dan Escherichia coli
}

\author{
Fantry Nurhayati Kadir*a, Max Revolta Jhon Runtuwenea, Vanda Silvana \\ Kamua \\ aJurusan Kimia, FMIPA, Universitas Sam Ratulangi, Manado
}

KATA KUNCI

Daun Sesewanua

(Clerodendron squamatum

Vahl.)

Kromatografi kolom

Kandungan total

Antibakteri

\begin{abstract}
A B S T R A K
Telah dilakukan penelitian mengenai kandungan total fenolik, flavonoid dan tanin terkondensasi dari hasil pemisahan kromatografi kolom dan uji aktivitas antibakteri fraksi daun sesewanua terhadap bakteri Streptococcus mutans dan escherecia coli. Pemisahan kromatografi kolom dimulai dengan proses ekstraksi maserasi menggunakan pelarut metanol. Hasil penelitian menunjukkan bahwa kandungan total fenolik tertinggi pada fraksi metanol yaitu $135,497 \mathrm{mg} / \mathrm{g}$, kandungan total flavonoid tertinggi pada fraksi etil asetat yaitu 102,647 mg/g dan kandungan total tanin terkondensasi tertinggi pada fraksi metanol yaitu $53,543 \mathrm{mg} / \mathrm{g}$. Uji aktivitas antibakteri menggunakan konsentrasi fraksi 40\%,60\% dan 80\% dilakukan sebanyak tiga kali pengulangan. Larutan DMSO 10\% digunakan sebagai kontrol negatif dan kloramfenikol sebagai kontrol positif. Hasil menunjukkan bahwa fraksi $n$-heksana tidak memiliki zona hambat sedangkan fraksi etil asetat dan fraksi metanol daun sesewanua dapat menghambat bakteri Streptococcus mutans dan Escherecia coli. Konsentrasi fraksi $80 \%$ menunjukkan zona hambat yang paling besar

A B S T R A C T

Research has been conducted on the total content of phenolics, flavonoids and condensed tannins from the results of column chromatography separation. Antibacterial activity test of leaf fractions was also performed against Streptococcus mutans and Escherecia coli. The separation of column chromatography was initialized with the process of maceration using methanol as solvents. The highest total phenolic content obtained in the methanol fraction was $135.497 \mathrm{mg} / \mathrm{g}$, the highest total flavonoid content obtained in the ethyl acetate fraction was 102.647 $\mathrm{mg} / \mathrm{g}$ and the highest total condensed tannin content in the methanol fraction was $53.543 \mathrm{mg} / \mathrm{g}$. Antibacterial activity test was done triplicates using the 40\%, 60\% and $80 \%$ fraction. DMSO $10 \%$ was apllied as the negative control and chloramphenicol as the positive control. The results showed that the $n$-hexane fraction did not have an inhibition zone while the ethyl acetate fraction and the methanol fraction of the leaves can inhibit Streptococcus mutans and Escherecia coli. Moreover, $80 \%$ fraction showed the largest inhibition zone.
\end{abstract}

\section{K E Y W O R D S}

Sesewanua leaf

(Clerodendron squamatum

Vahl.),

Column chromatography

Total Content

Antibacterial.
TERSEDIA ONLINE

01 Agustus 2021

\section{Pendahuluan}

Indonesia memiliki \pm 30.000 jenis tumbuhan dan \pm 7000 jenis berkhasiat obat ( $90 \%$ spesies tumbuhan obat di kawasan Asia). Selain itu, Indonesia juga diakui sebagai salah satu bagian dunia yang masih menyisakan kehidupan liar sebagai gudang keanekaragaman spesies tumbuhan untuk memenuhi kebutuhan manusia masa kini maupun masa yang akan datang (Simbala, 2016).
Tumbuhan sesewanua (Clerodendron squamatum Vahl.) banyak dimanfaatkan oleh masyarakat Di Sulawesi Utara untuk mengobati berbagai macam penyakit yaitu menghilangkan nyeri pada gigi, demam penyebab diare, patah tulang dan penurunan radang yang disebabkan oleh bakteri (Huliselan et al., 2015).

Penelitian sebelumnya melaporkan bahwa daun sesewanua secara ilmiah memiliki aktivitas biologis sebagai antipiretik atau antidemam (Moot et al., 2013) 
dan Yudistira (2017) melaporkan bahwa ekstrak daun sesewanua memiliki aktivitas antikanker serta Inhibition Concentration 50\% $\left(\mathrm{IC}_{50}\right)=359,44 \mu \mathrm{g} / \mathrm{mL}$. Hasil penelitian Huliselan et al. (2015) melaporkan bahwa ekstrak daun sesewanua mengandung senyawa metabolit sekunder seperti fenolik, flavonoid dan alkaloid.

Adanya kandungan senyawa yang dapat bekerja sebagai antibakteri membuat daun sesewanua berpotensi sebagai antibakteri terhadap bakteri Grampositif dan Gram-negatif. Streptococcus mutans merupakan bakteri Gram-positif yang biasanya ditemukan dalam rongga mulut manusia, hal ini memyebabkan gigi mengalami berbagai infeksi karena faktor-faktor tertentu yang mendukung pertumbuhan bakteri dan Escherecia coli merupakan bakteri Gramnegatif yang biasanya ditemukan dalam usus besar manusia yang sering menimbulkan infeksi pada saluruan kemih, saluran empedu dan tempat-tempat lain di rongga perut yang menyebabkan diare (Manton, 2010; Mahon, 2015).

Untuk pemisahan senyawa metabolit sekunder daun sesewanua dilakukan banyak hal salah satunya kromatografi kolom. Kromatografi kolom adalah salah satu metode pemisahan senyawa dalam jumlah besar dan berkaitan dengan perbedaan antara gaya-gaya antar molekul dalam sampel dengan fasa gerak dan antara komponen dengan fasa diam. Tekniknya bergantung pada kombinasi fasa diam dan fasa gerak yang dipilih. (Rubiyanto, 2017).

\section{Material dan Metode \\ Material}

Peralatan yang digunakan yaitu alat-alat gelas dalam laboratorium, blender, aluminium foil, ayakan, timbangan analitik, seperangkat alat distilasi, seperangkat alat kromatografi kolom, oven, rotary evaporator, waterbath, desikator, kertas saring, sudip, cawan porselin, cawan petri, pipet tetes, jarum ose, autoklaf, lampu spritus, vortex, mikro pipet, mistar berskala, laminar air flow, inkubator, pinset, spektrofotometer (UV-Vis). Bahan yang digunakan adalah sampel daun Sesewanua, bakteri uji S. mutans dan $E$. coli, metanol teknis $\left(\mathrm{CH}_{3} \mathrm{OH}\right)$, $n$-heksana teknis $\left(\mathrm{C}_{6} \mathrm{H}_{14}\right)$, etil asetat teknis $\left(\mathrm{C}_{4} \mathrm{H}_{8} \mathrm{O}_{2}\right)$, aquades $\left(\mathrm{H}_{2} \mathrm{O}\right)$, nutrient agar (NA), kuarsetin $\left(\mathrm{C}_{15} \mathrm{H}_{10} \mathrm{O}_{7}\right)$, katekin $\left(\mathrm{C}_{15} \mathrm{H}_{14} \mathrm{O}_{6}\right)$, asam galat $\left(\mathrm{C}_{7} \mathrm{H}_{6} \mathrm{O}_{5}\right)$, vanillin $\left(\mathrm{C}_{8} \mathrm{H}_{8} \mathrm{O}_{3}\right)$, pelarut dimetilsulfoksida $\left(\mathrm{C}_{2} \mathrm{H}_{6} \mathrm{OS}\right)$, asam klorida $(\mathrm{HCl})$, aluminium klorida $\left(\mathrm{AlCl}_{3}\right)$, natrium karbonat $\left(\mathrm{Na}_{2} \mathrm{CO}_{3}\right)$, asam sulfat $\left(\mathrm{H}_{2} \mathrm{SO}_{4}\right)$, barium klorida dihidrat $\left(\mathrm{BaCl}_{2} \cdot 2 \mathrm{H}_{2} \mathrm{O}\right)$ $1,175 \%$, sodium klorida $(\mathrm{NaCl})$ 0,9\%, vaselin, folin ciocalteau, spritus, kertas cakram, kertas cakram kloramfenikol, kapas steril dan silica gel $\mathrm{GF}_{254}$.

\section{Metode}

\section{Pengambilan Sampel dan Preparasi Sampel}

Sampel yang digunakan pada penelitian ini yaitu daun Sesewanua (C. squamatum Vahl.), yang diambil di Desa Kali Kecamatan Pineleng. Daun Sesewanua (C. squamatum Vahl.) yang telah dikumpulkan dibersihkan dari kotoran, selanjutnya dicuci dengan air sampai bersih, ditiriskan, lalu dikeringkan dengan cara diangin-anginkan. Sampel yang telah kering diserbukkan dengan menggunakan blender, serbuk yang dihasilkan diayak menggunakan ayakan mesh 65 hingga diperoleh serbuk yang halus. Hasilnya dimasukkan ke dalam wadah gelas tertutup.

\section{Penentuan Kadar Air}

Penentuan kadar air dilakukan dengan metode pemanasan menggunakan oven. Sampel ditimbang sebanyak 2 gram didalam cawan porselin, dimasukkan dalam oven dengan temperatur pemanasan $105{ }^{\circ} \mathrm{C}$ selama 3 jam, kemudian didinginkan dalam desikator selama 30 menit, lalu sampel ditimbang. Kemudian dipanaskan kembali dengan oven dan didinginkan sampai mencapai berat konstan (Kumesan et al., 2017). Kadar air dihitung berdasarkan rumus :

kadar air $=\frac{(\mathrm{A}+\mathrm{B})-\mathrm{C}}{\mathrm{B}} \times 100 \%$

Keterangan :

$\mathrm{A}=$ berat wadah

$\mathrm{B}=$ berat sampel sebelum dipanaskan

$\mathrm{C}=$ berat sampel + wadah setelah dipanaskan

\section{Ekstraksi}

Ekstraksi dilakukan dengan cara maserasi menggunakan pelarut metanol. Ditimbang $1000 \mathrm{~g}$ simplisia daun sesewanua lalu ditambahkan $4 \mathrm{~L}$ pelarut hingga simplisia terendam seluruhnya. Ekstraksi dilakukan selama 3 × 24 jam terlindung dari cahaya dan dilakukan pengadukan setiap 24 jam. Pada hari ke 2 dan ke 3 pelarut disaring sehingga diperoleh filtrat lalu semua filtrat digabungkan kemudian filtrat dievaporasi pada suhu $60^{\circ} \mathrm{C}$ dengan rotatory evaporator lalu diuapkan dalam oven dengan suhu $40^{\circ} \mathrm{C}$ sehingga diperoleh ekstrak kental (Ngazizah et al., 2016). Hasil rendemen ekstrak daun sesewanua dapat dihuting dengan rumus berikut :

$\%$ rendemen $=\frac{\text { Bobot ektrak yang diperoleh }(\mathrm{gram})}{\text { Bobot simplisia sebelum diekstraksi }(\mathrm{gram})} \times 100 \%$

\section{Pemisahan dengan Kromatografi Kolom}

Ekstrak daun sesewanua sebanyak 20 g dimasukkan ke dalam kolom yang telah diisi dengan silika gel $\mathrm{GF}_{254}$ yang telah direndam selama 1x24 jam, dipisahkan dengan masing-masing pelarut $n$ heksana, etil asetat dan metanol, kemudian masingmasing pelarut yang menetes ditampung dalam erlenmeyer dan di uapkan dalam oven $40^{\circ} \mathrm{C}$ (Isma, 2017).

\section{Penentuan Kandungan Total Fenolik}

Penentuan total fenolik menggunakan metode Conde et al. (1997). Sebanyak 0,1 mL larutan masing-masing fraksi $n$-heksan, fraksi etil asetat dan fraksi daun sesewanua dimasukakan dalam tabung reaksi, lalu ditambahkan $0,1 \mathrm{~mL}$ reagen Folin Ciocalteau 50\%. Kemudian divorteks, lalu ditambahkan $2 \mathrm{~mL}$ larutan $\mathrm{Na}_{2} \mathrm{CO}_{3} 2 \%$ dan divortex. Selanjutnya, campuran diinkubasi dalam ruangan gelap selama 30 menit. Absorbansi ekstrak dibaca pada spektrofotometer UV-Vis dengan panjang gelombang $750 \mathrm{~nm}$. Kandungan total fenolik dinyatakan sebagai $\mathrm{mg} / \mathrm{g}$ ekstrak. Kurva kalibrasi menggunakan asam galat sebagai standar. 


\section{Penentuan Kandungan Total Flavonoid}

Penentuan total flavonoid menggunakan metode Meda et al. (2005). Sebanyak $1 \mathrm{~mL}$ larutan masingmasing fraksi n-heksan, fraksi etil asetat dan fraksi daun seesewanua dimasukkan ke dalam tabung reaksi, kemudian ditambahkan dengan $2 \mathrm{~mL} \mathrm{AICl3}$ $2 \%$ yang telah dilarutkan dalam metanol, kemudian divorteks dan dibaca absorbansinya pada panjang gelombang $415 \mathrm{~nm}$. Kandungan total flavonoid dinyatakan sebagai $\mathrm{mg} / \mathrm{g}$ ekstrak. Kurva kalibrasi menggunakan kuersetin sebagai standar.

\section{Penentuan Kandungan Total Tanin Terkondensasi}

Kandungan tannin terkondensasi sampel ditentukan menurut metode (Julkunan-Titto, 1985). Sebanyak 0,1 mL fraksi $n$-heksan, fraksi etil asetat dan fraksi metanol daun sesewanua masing-masing dimasukkan ke dalam tabung reaksi yang dibungkus alumunium foil, lalu ditambahkan $2 \mathrm{~mL}$ larutan vanillin $4 \%$ dalam metanol dan divortex. Segera sesudah ditambahkan $1,5 \mathrm{~mL} \mathrm{HCl}$ pekat dan divorteks lagi. Absorbansi dibaca pada panjang gelombang $500 \mathrm{~nm}$ setelah campuran diinkubasi selama 20 menit pada suhu kamar. Hasilnya diplotkan terhadap kurva standar katekin yang dipersiapkan dengan cara yang sama. Kandungan tannin terkondensasi dinyatakan dalam $\mathrm{mg} / \mathrm{g}$ ekstrak. Kurva kalibrasi menggunakan katekin sebagai standar.

Aktivitas Antibakteri (Hafizah et al., 2015)

\section{Sterilisasi Alat}

Alat-alat yang digunakan dalam penelitian uji aktivitas antibakteri ini disterilkan dalam autoklaf pada suhu $121^{\circ} \mathrm{C}$ selama 15 menit.

\section{Pembuatan Media}

1) Pembuatan nutrient agar (NA)

Timbang masing-masing nutrient agar sebanyak 3 gram kemudian larutkan dalam $100 \mathrm{~mL}$ aquades kemudian dimasukkan ke dalam 2 erlemenyer dan disterilkan dalam autoklaf selama 15 menit pada suhu $121^{\circ} \mathrm{C}$.

2) Pembuatan larutan uji dari fraksi daun sesewanua

Fraksi $n$-heksan, etil asetat dan metanol dilarutkan dengan DMSO 10\%, dibuat larutan stok $100 \%$ lalu diencerkan $0,8 \mathrm{~mL}, 0,6 \mathrm{~mL}$ dan $0,4 \mathrm{~mL}$ sehingga menghasilkan larutan uji 80\%, 60\%, 40\%. Dengan kontrol positif digunakan kertas cakram kloramfenikol dan untuk kontrol negatif digunakan larutan DMSO 10\%.

\section{Pembuatan Larutan Standar Mc. Farland}

Larutan H2SO4 1\% sebanyak 9,95 mL dicampurkan dengan larutan $\mathrm{BaCl} 2.2 \mathrm{H} 20$ 1,175\% sebanyak 0,5 $\mathrm{mL}$ dalam Erlenmeyer. Larutan kemudian dikocok sampai terbentuk larutan yang keruh.
Biakan hasil peremajaan diambil 1 ose pada media nutrient agar, lalu disuspensikan dalam natrium klorida ( $\mathrm{NaCl}) \quad 0,9 \%$ dan dikocok. Pertumbuhan bakteri ditandai dengan adanya kekeruhan.

\section{Pengujian Aktivitas Antibakteri}

Disiapkan 2 medium nutrient agar masingmasing sebanyak $150 \mathrm{~mL}$ dicampurkan suspensi bakteri masing-masing dengan bakteri S. mutans dan E. coli sebanyak 4,5 $\mathrm{mL}$ kemudian dimasukkan kedalam cawan petri didiamkan hingga medium memadat. Kemudian dimasukkan masing-masing kertas cakram ke konsentrasi 80\%, 60\%, 40\% pada fraksi n-heksan, fraksi etil asetat dan fraksi metanol. Untuk kontrol positif (+) digunakan kertas cakram kloramfenikol $30 \mu \mathrm{g}$ dan kontrol negatif (-) digunakan larutan DMSO 10\% direndam kertas cakram \pm 15 menit. Kertas cakram yang telah mengandung fraksi n-heksan, fraksi etil setat dan fraksi metanol masingmasing dimasukkan ke dalam permukaan medium nutrient agar yang berisi bakteri $S$. mutans dan $E$. coli. Kemudian diinkubasi pada suhu $37^{\circ} \mathrm{C}$ selama 1x24 jam.

\section{Analisis Data}

Analisis data menggunakan SPSS ver. 25 dengan uji Duncan dengan derajat kepercayaan >0,05.

\begin{tabular}{|c|c|c|}
\hline \multicolumn{3}{|c|}{ Hasil dan Pembahasan } \\
\hline \multicolumn{3}{|c|}{$\begin{array}{l}\text { Kadar Air } \\
\text { Kadar air pada daun sesewanua memiliki } r \\
\text { 8,62\%. Hasil kadar air dapat dilihat pada tabel } 1 . \\
\text { Tabel 1. Kadar Air Serbuk Daun Sesewanua }\end{array}$} \\
\hline $\begin{array}{c}\text { Pengujian } \\
\text { ke- }\end{array}$ & Kadar Air (\%) & $\begin{array}{c}\text { Rata-rata } \\
\text { (\%) }\end{array}$ \\
\hline $\mathrm{I}$ & 8,67 & \multirow{2}{*}{8,62} \\
\hline II & 8,57 & \\
\hline
\end{tabular}

Hasil yang didapatkan berada pada persentase kurang dari $10 \%$ yang berarti sesuai dengan syarat mutu kadar air yang telah ditentukan oleh SNI. Semakin rendah nilai kadar air sampel maka akan semakin memudahkan pelarut untuk mengekstrak komponen senyawa aktif (Nurdyansyah et al., 2019).

\section{Ekstraksi}

Menurut Rosidah \& Tjitraresmi (2018) pelarut metanol diduga mempunyai sifat yang dapat melarutkan semua jenis komponen yang berupa senyawa polar, non polar dan semi polar. Pada proses maserasi dilakukan pengadukan berulang atau sesekali diaduk untuk memaksimalkan penyarian, sehingga permukaan pelarut masuk ke seluruh permukaan serbuk simplisia. Pengadukan diperlukan untuk menghomogenkan larutan selama proses perendaman dan mempercepat kontak antara sampel dan pelarut. Hasil ekstrak $1000 \mathrm{~g}$ daun sesewanua dengan pelarut metanol adalah 135,897 gram (rendemen yaitu 13,58\%). 
Pemisahan dengan Kromatografi Kolom

Tabel 2. Rendemen Hasil Pemisahan Ekstrak Daun

Sesewanua

\begin{tabular}{ccc}
\hline Hasil Fraksi & Massa (g) & Rendemen (\%) \\
\hline FH & 1,6724 & 8,362 \\
FEA & 4,2117 & 21,058 \\
FM & 5,8761 & 29,380 \\
\hline
\end{tabular}

Keterangan : FH=Fraksi Heksana; FEA=Fraksi Etil Asetat; FM=Fraksi Metanol

Berdasarkan data pada Tabel 2, fraksi metanol memiliki rendemen yang paling tinggi. Hal ini dikarenakan tingginya rendemen fraksi metanol mampu mengekstrak lebih banyak komponen bioaktif dengan sifat kepolaran tinggi pada daun sesewanua lebih banyak mengandung senyawa bersifat polar (Salamah \& Widyasari, 2015).

\section{Kandungan Total Fenolik}

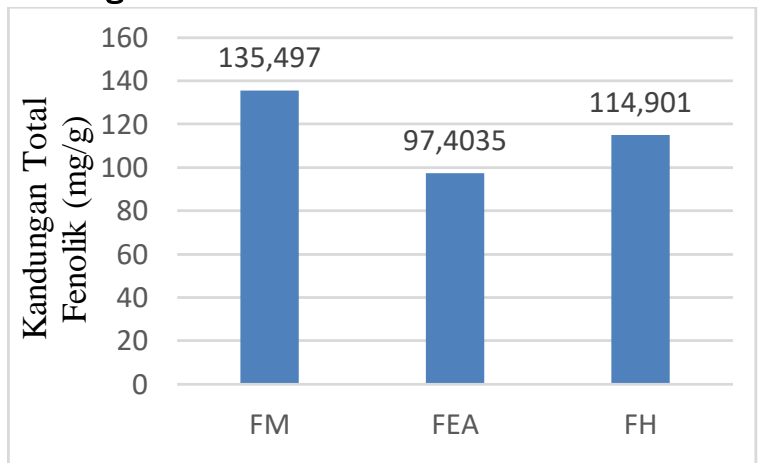

Gambar 1. Kandungan Total Fenolik (FM=Fraksi Metanol; FEA=Fraksi Etil Asetat; FH=Fraksi Heksana).

Berdasarkan Gambar 1. dapat diketahui bahwa fraksi metanol daun sesewanua memiliki kandungan fenolik lebih tinggi dibandingkan dengan fraksi $n$ heksana dan fraksi etil asetat. Hal ini menunjukkan bahwa fenolik larut dalam pelarut polar. Menurut Gumolung (2018) fraksi metanol mempunyai kandungan fenolik total yang paling besar, karena sebagaian besar senyawa fenolik dalam bentuk glikosida lebih mudah larut dalam pelarut metanol.

\section{Kandungan Total Flavonoid}

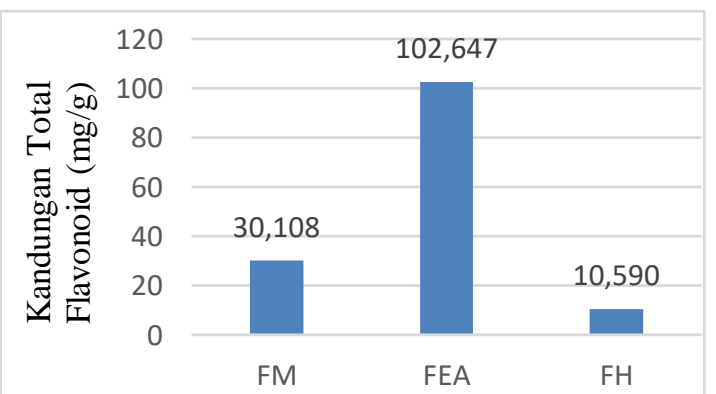

Gambar 2. Kandungan Total Flavonoid (FM=Fraksi Metanol; FEA=Fraksi Etil Asetat; FH=Fraksi Heksana).

Berdasarkan Gambar 2. kandungan total flavonoid daun sesewanua yang tertinggi diperoleh pada fraksi etil asetat diikuti fraksi metanol dan fraksi $n$-heksana. Hal ini menunjukkan bahwa flavonoid aglikon atau flavonoid larut dalam pelarut semi polar. Menurut Tanaya et al. (2015) flavonoid aglikon seperti isoflavon, flavanon dan flavon serta flavonol yang termetoksilasi cenderung lebih larut dalam pelarut yang semi polar seperti eter, kloroform, etil asetat dan n-butanol, sedangkan flavonoid glikosida lebih larut dalam pelarut yang lebih polar seperti metanol.

\section{Kandungan Total Tanin Terkondensasi}

Penentuan kandunagn total tanin terkondensasi diperoleh dari persamaan regresi kurva standar kuersetin $y=0,0178 x-0,3074$

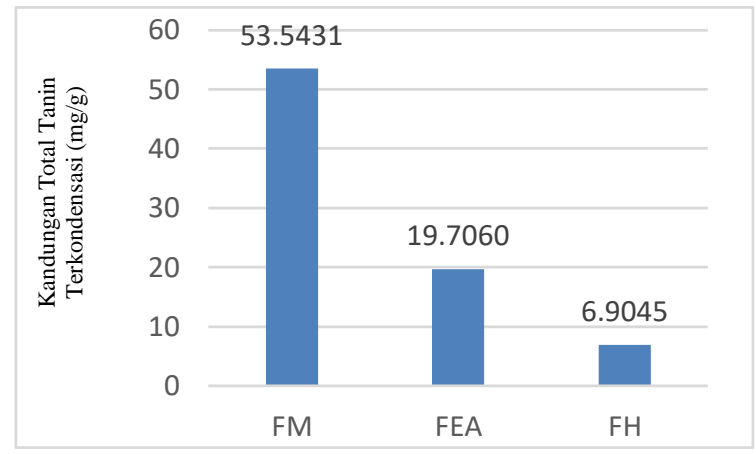

Gambar 3. Kandungan Total Tanin Terkondensasi (FM=Fraksi Metanol; FEA=Fraksi Etil Asetat; FH=Fraksi Heksana)

Berdasarkan Gambar 3. dapat diketahui bahwa total tanin terkondensasi tertinggi daun sesewanua pada fraksi metanol diikuti fraksi etil asetat, dan fraksi $n$ heksana. Tanin memiliki sifat kelarutan sangat mudah larut dalam pelarut polar seperti air, metanol dan etanol (Amelia, 2015). Hal ini sesuai dengan hasil penentuan total tanin pada daun sesewanua, dimana fraksi dengan pelarut yang bersifat polar memiliki nilai total tanin terkondensasi paling tinggi sedangkan fraksi dengan pelarut non polar memiliki total tanin terkondensasi paling kecil.

\section{Hasil Pengujian Aktivitas Antibakteri}

Berdasarkan hasil pengamatan zona hambat fraksi daun sesewanua terhadap pertumbuhan bakteri Gramnegatif ( $E$. coli) dan Gram-positif (S. mutans) menunjukkan adanya zona hambat terhadap pertumbuhan bakteri tersebut. Pada tabel 3 dapat dilihat hasil rata-rata zona hambat fraksi terhadap bakteri E.coli dan S.mutans. Sedangkan hasil uji aktivitas antibakteri fraksi $n$-heksan, etil asestat dan metanol terhadap bakteri E.coli dan S.mutans dapat dilihat pada Gambar 4., Gambar 5. dan Gambar 6.

Pengujian aktivitas antibakteri dari fraksi n-heksana, etil asetat dan metanol yang dilakukan dengan metode difusi cakram didapatkan hasil fraksi $n$-heksana tidak memiliki zona hambat terhadap kedua bakteri uji karena fraksi $n$-heksana tidak mampu menarik senyawa antibakteri yang ada pada daun sesewanua, sehingga tidak mampu menghambat pertumbuhan bakteri $E$. coli dan S. mutans. Sedangkan fraksi etil asetat dan metanol memiliki zona hambat dari berbagai variasi konsentrasi dikedua bakteri uji.

Berdasarkan hasil total senyawa fenolik, flavonoid dan tanin lebih banyak terkandung dalam pelarut metanol hal ini dikarenakan metanol bersifat polar dibandingkan dengan etil asetat, sehingga fraksi metanol memiliki zona hambat yang paling besar dibandingkan 
dengan fraksi lainnya. Perbedaan zona hambat dapat disebabkan oleh jumlah zat aktif antibakteri yang terkandung didalam fraksi, semakin banyak senyawa antibakteri didalam fraksi semakin bagus cara kerja fraksi dalam menghambat pertumbuhan bakteri.

\begin{tabular}{|c|c|c|c|}
\hline \multirow{2}{*}{ Fraksi } & \multirow{2}{*}{ Konsentrasi } & \multicolumn{2}{|c|}{$\begin{array}{l}\text { Diameter Zona Hambat Pertumbuhan Bakteri } \\
\text { (mm) (Rata-rata } \pm \text { SD) }\end{array}$} \\
\hline & & $\begin{array}{l}\text { Gram-negatif } \\
\text { (E. coli) }\end{array}$ & $\begin{array}{l}\text { Gram-positif } \\
\text { (S. mutans) }\end{array}$ \\
\hline \multirow{3}{*}{ n-heksana } & $40 \%$ & $0 \pm 0,00^{\mathrm{a}}$ & $0 \pm 0,00^{\mathrm{a}}$ \\
\hline & $60 \%$ & $0 \pm 0,00^{\mathrm{a}}$ & $0 \pm 0,00^{\mathrm{a}}$ \\
\hline & $80 \%$ & $0 \pm 0,00^{\mathrm{a}}$ & $0 \pm 0,00^{\mathrm{a}}$ \\
\hline \multirow{3}{*}{ Etil asetat } & $40 \%$ & $9,37 \pm 0,16^{b}$ & $9,68 \pm 0,63^{b}$ \\
\hline & $60 \%$ & $9,45 \pm 0,13^{b}$ & $10,27 \pm 1,37^{b c}$ \\
\hline & $80 \%$ & $9,5 \pm 0,13^{b}$ & $10,63 \pm 1,75^{b c}$ \\
\hline \multirow{3}{*}{ Metanol } & $40 \%$ & $9,97 \pm 0,60^{b}$ & $10,98 \pm 0,48^{\mathrm{bcd}}$ \\
\hline & $60 \%$ & $10,85 \pm 0,36^{c}$ & $11,75 \pm 1,04^{\text {cd }}$ \\
\hline & $80 \%$ & $11,28 \pm 0,65^{\circ}$ & $12,33 \pm 1,43^{d}$ \\
\hline 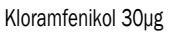 & $(+)$ & $21,35 \pm 1,16^{d}$ & $21,47 \pm 0,06^{e}$ \\
\hline DMSO 10\% & $(-)$ & $0 \pm 0,00^{\mathrm{a}}$ & $0 \pm 0,00^{\mathrm{a}}$ \\
\hline
\end{tabular}
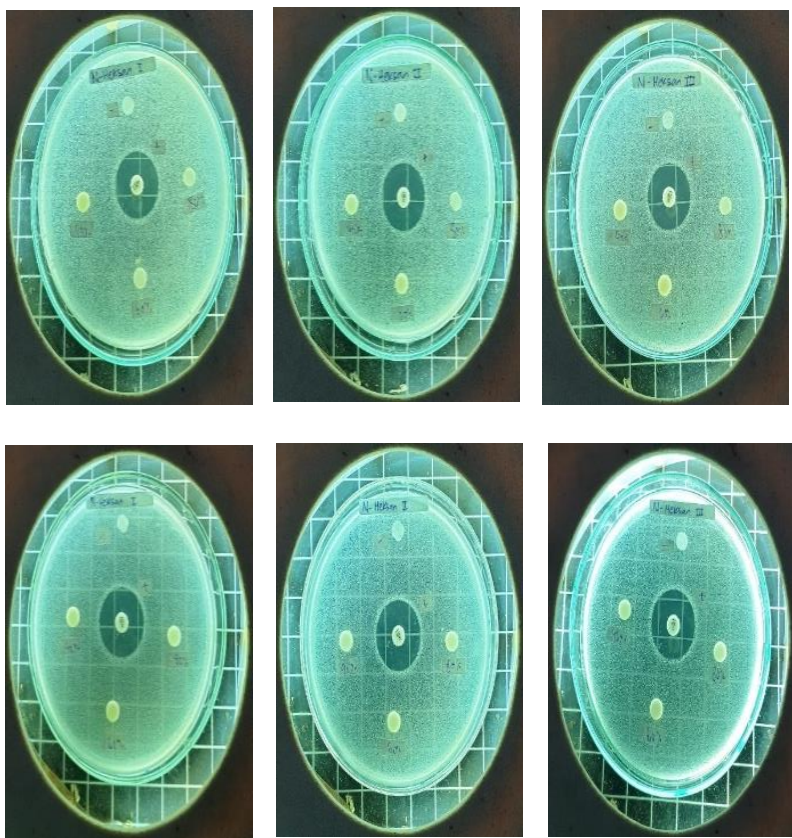

Gambar 4. Hasil Uji Aktivitas Antibakteri Fraksi n-heksan terhadap Bakteri E.coli dan S.muntas
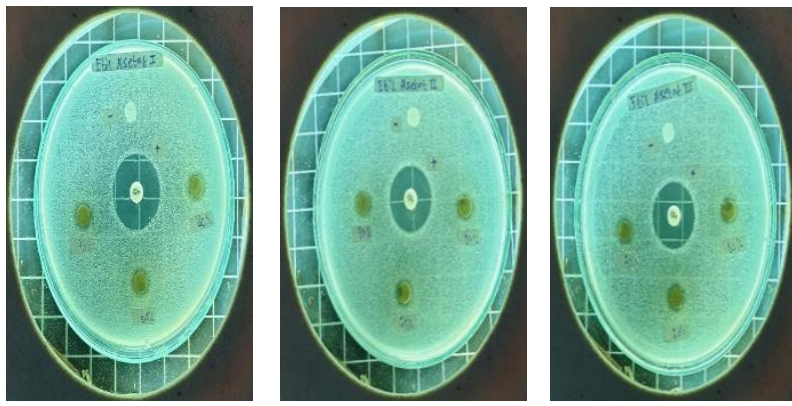
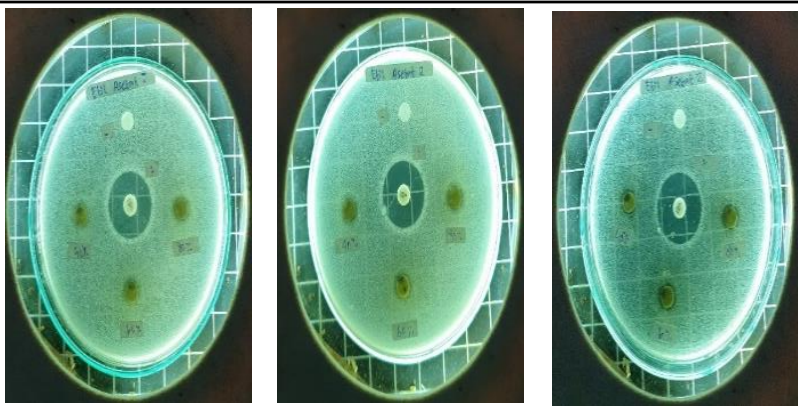

Gambar 5. Hasil Uji Aktivitas Antibakteri Fraksi Etil Asetat terhadap Bakteri E.coli dan S.muntas
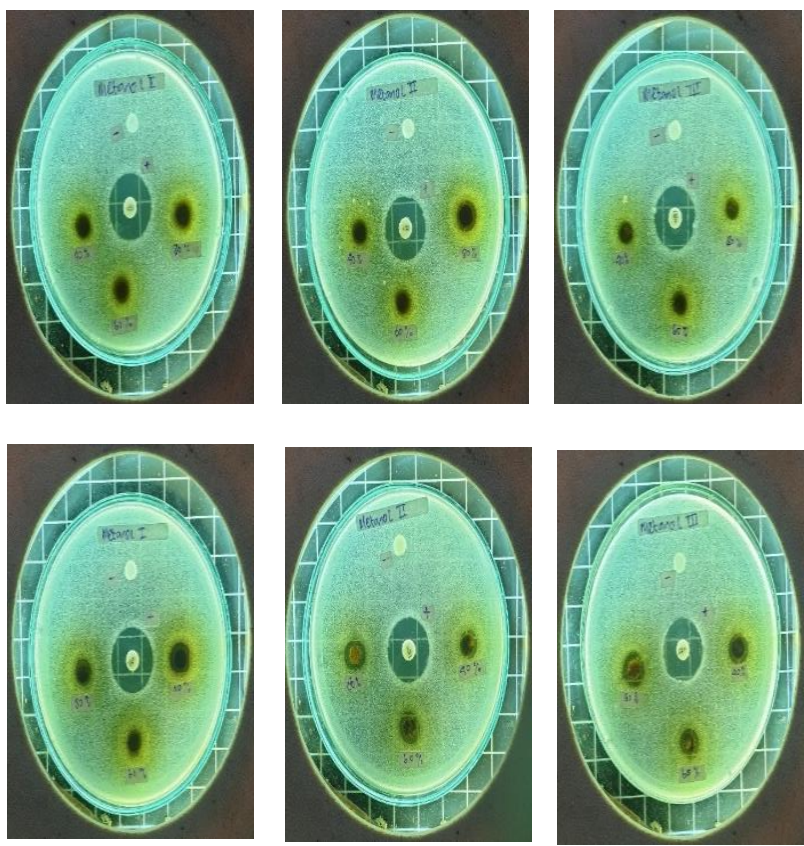

Gambar 6. Hasil Uji Aktivitas Antibakteri Fraksi Metanol terhadap Bakteri E.coli dan S.muntas

Pada kontrol positif menunjukkan terbentuknya zona hambat yang diperoleh lebih besar dari variasi konsentrasi fraksi etil asetat dan fraksi metanol, dimana kontrol positif yang digunakan adalah kloramfenikol. Hal ini disebabkan karena kloramfenikol termasuk dalam golongan antibiotik berspektrum luas yang mampu menghambat pertumbuhan Gram-positif dan Gramnegatif (Utomo et al., 2018). Kontrol negatif yang digunakan adalah DMSO 10\% dan hasil yang diperoleh tidak memberikan efek antibakteri pada kedua fraksi uji yang terlihat dengan tidak terbentuknya zona hambat.

Berdasarkan tabel 3 dapat dilihat nilai zona hambat yang dihasilkan aktivitas antibakteri fraksi daun sesewanua lebih efektif untuk bakteri $S$. mutans dibandingkam dengan bakteri $E$. coli hal ini dikarenakan adanya perbedaan struktur dinding sel, sehingga menyebabkan perbedaan kesensitifitan terhadap senyawa antibakteri tertentu 
Kesimpulan

Berdasarkan hasil penelitian yang dilakukan diperoleh dapat disimpulkan bahwa kandungan total flavonoid tertinggi ada pada fraksi etil asetat, sedangkan kandungan total fenolik dan total tanin terkondensasi tertinggi ada pada fraksi metanol daun sesewanua. Hasil uji antibakteri menunjukkan bahwa fraksi $n$-heksana tidak memiliki zona hambat sedangkan fraksi etil asetat dan fraksi metanol daun sesewanua dapat menghambat pertumbuhan bateri S. mutans dan E. coli dengan konsentrasi fraksi $80 \%$ memiliki zona hambat yang paling besar.

\section{Daftar Pustaka}

Amelia, F. R. 2015. Penentuan Jenis Tanin dan Penetapan Kadar Tanin dari Buah Bungur Muda (Lagerstreomia speciosa Pers.) secara Spektofotometri dan Permanganometri. Jurnal IImiah Mahasiswa Universitas Surabaya. 4(2): 120.

Conde, E., E. Cadahia., M. C. Garcia-Vallejo., B. F. de Simon. \& J. R. G. Adrabos. 1997. Low Molecular Weight Polyfenol in Cork of Quercus Suber. Journal of Agricultural \& Food Chemistry. 45(7): 2695-2700.

Gumolung, D. 2018. Analisis Kandungan Total Fenolik pada Jonjot Buah Labu Kuning (Cucurbita moschata). Fullerene Journal of Chemistry. 3(1): 1-4.

Hafizah, I., N. I. Akib. \& M. Fajrianto. 2015. Uji Aktivitas Antibakteri Ekstrak Metanol Rumput Laut (Eucheuma $s p$ ) pada berbagai Tingkat Konsentrasi terhadap Pertumbuhan Bakteri Escherichia coli dan Staphylococcus aureus. Jurnal Medula. 1(2): 64-70.

Huliselan, Y. M., M. R. J. Runtuwene. \& D. S. Wewengkang. 2015. Aktivitas Antioksidan Ekstrak Etanol, Etil Asetat, dan n-Heksan dari Daun Sesewanua (Cleodendron squamatum Vahl.). Pharmacon Jurnal IImiah Farmasi. 4(3): 155-163.

Isma, M. L. 2017. Uji Aktivitas Fraksi Aktif Ekstrak Kulit Batang Garcinia dioica Blume terhadap Enzim Malate: Quinone Oxidoreductase dari Plasmodium falciparum (PfMQO). [Skripsi]. Fakultas Kedokteran dan IImu Kesehatan Universitas Islam Negeri Syarif Hidayatullah : Jakarta.

Julkunen-Tiitto, R. 1985. Phenolics Constituents in the Leaves of Northern Willows: Methods for the Analysis of Certain Phenolics. Journal of Agricultural \& Food Chemistry. 33(2):213-217.

Kumesan, E. C., V. Pandey. \& H. J. Lohoo. 2017. Analisa Total Bakteri, Kadar Air dan pH pada Rumput Laut (Kappaphycus alvarezii) dengan Dua Metode Pengeringan. Jurnal Media Teknologi Perikanan. 5(1):124-129.

Mahon, C. R., D. C. Lehman. \& G. Manuselis. 2015. Texbook of Diagnostic Microbiologi. Saunders Elsevier, USA.
Manton, J. W. 2010. Streptococcus mutans and You : Home Sweet Home in your mouth. Microbiology Fall, London.

Meda, A., C. E. Lamien., M. Romito., J. Millogo. \& O. G. Nacoulma. 2005. Determination of the Total Phenolic, Flavonoid \& Proline Contents in Burkina Fasan Honey, as well as Their Radical Scavenging Activity. Journal of Food Chemistry. 91(3): 571577.

Moot, C. L., W. Bodhi. \& J. Mongi. 2013. Uji Efek Antipiretik Infusa Daun Sesewanua (Cloredondron squamatum Vahl.) terhadap Kelinci Jantan yang Diinduksi Vanksi DTP HB. Jurnal Pharmacon. 2(3): 58-61.

Ngazizah, F. N., N. Ekowati. \& A. T. Septiana. 2016. Potensi Daun Trembilungan (Begonia hirtella Link) sebagai Antibakteri dan Antifungi. Biosfera. 33(3): 126-133.

Nurdyansyah, F., D. A. Widyasturi. \& A. A. Mandasari. 2019. Karakteristik Simplisia \& Ekstrak Etanol Kulit Petai (Parkia speciosa) dengan Metode Maserasi. Semarang : Seminar Nasional \& Enterpreunership VI.

Rosidah., \& A. Tjitraresmi. 2018. Potensi Tanaman Melastomataceae sebagai Antioksidan. Farmaka. 1(16): 24-33.

Rubiyanto. 2017. Metode Kromatografi Prinsip Dasar, Praktikum dan Pendekatan Pembelajaran Kromatografi edisi 1. Yogyakarta : CV Budi Utama.

Salamah, N. \& E. Widyasari. 2015. Aktivitas Antioksidan Ekstrak Metanol Daun Kelengkeng (Euphoria Iongan (L) Steud.) dengan Metode DPPH. Pharmaciana. 5(1): 25-34.

Simbala, H. E. I. 2016. Proses Produksi dan Formulasi Produk Ekstrak Buah Pinang Yaki Areca Vestiaria Sebagai Bahan Aktif Produk Fitofarmaka Antikanker. Universitas Sam Ratulangi, Manado.

Tanaya, V., R. Retnowati. \& Suratmo. 2015. Fraksi Semi Polar dari Daun Mangga Kasturi (Mangifera casturi Kosterm). Kimia Student. 1(1): 778-784.

Utomo, S. B., M. Fujiyanti., W. P. Lestari. \& S. Mulyani. 2018. Uji Aktivitas Antibakteri Senyawa C-4Metoksifenilkaliks [4] Resorsinarena Termodifikasi Hexadecyltrimethtl ammoniumBromide terhadap Bakteri Staphylococcus aureus dan Eschericia coli. Jurnal Kimia dan Pendidikan Kimia. 3(3): 201-209.

Yudistira, A. 2017. Uji Aktivitas Antikanker Payudara Ekstrak Daun Sesewanua (Clerodendron squamatum Vahl.) terhadap Sel Kanker Payudara T47D. Pharmacon. 6(2): 45-51 